\title{
Note
}

\section{Thermal Stratification Phenomena in a 4-strand CC Tundish during Teeming of Steel-Water Model Study}

\section{Introduction}

With a view to simulating the thermal stratification taking place in 4-strand continuous casting tundish as a result of the drop in temperature in the ladle due to the long teeming duration a water model study was conducted. The model employed is shown in Fig. 1 with the dimensional details and the configurational arrangements. The flow pattern is also sketched in the figure. Literature on thermal stratification is scanty. ${ }^{1-5)}$

\section{Experimental}

The experimental arrangement consisted of allowing hot water at $70^{\circ} \mathrm{C}$ in a $50 \mathrm{l}$ container to enter through $12 \mathrm{~mm}$ dia. downstream nozzle into model tundish containing $52 l$ of water at room temperature to the level of $18 \mathrm{~cm}$. Such a system was selected for this study to simulate the industrial conditions of uncovered ladle during teeming where temperature drop occurs. The tundish temperature also changes and the metal falling from the ladle experiences buoyancy effects bringing about marked changes in the pattern of inflow and temperature profile in the tundish. This would also have significant influence on the inclusion floatation patterns. In the present arrangement, therefore, four sensitive thermometers were placed at locations shown in Fig. 1 ( $A$ and $C$ are located $2 \mathrm{~cm}$ below the surface at 10 and $65 \mathrm{~cm}$ away from the downstream entry, B and D are at bottom vertically below $\mathrm{A}$ and $\mathrm{C}$ respectively) to record the temperature changes occurring at these locations which are regions of importance due to the complex nature of fluid flow. Zones of maximum turbulence and mixed flow behaviour have been represented by these locations. Temperature at these locations were monitored at regular intervals of time after the commencement of hot water entry. into the tundish. The temperature changes occurring in ladle during teeming were also monitored at intervals with the help of thermometer placed near the downstream shown in Fig. 1. Simultaneously tracer studies were also conducted by injecting known quantity of dilute acid at the entry region as soon as the hot water is released, the concentration data were collected at predetermine time after injection in both inner and outer orifices of the tundish.

In the present setup shown in Fig. 1 dam and weir having heights of 5 and $7 \mathrm{~cm}$ were placed at 40 and $10 \mathrm{~cm}$ away from the downstream entry plane respectively. This configuration had given good fluid flow behaviour in earlier experiments conducted by the authors.

\section{Results}

\subsection{Temperature Distribution (Fig. 2)}

The container temperature drops from 70 by $25^{\circ} \mathrm{C}$ in $1200 \mathrm{~s}$ simulating roughly the drop in the ladle tem-

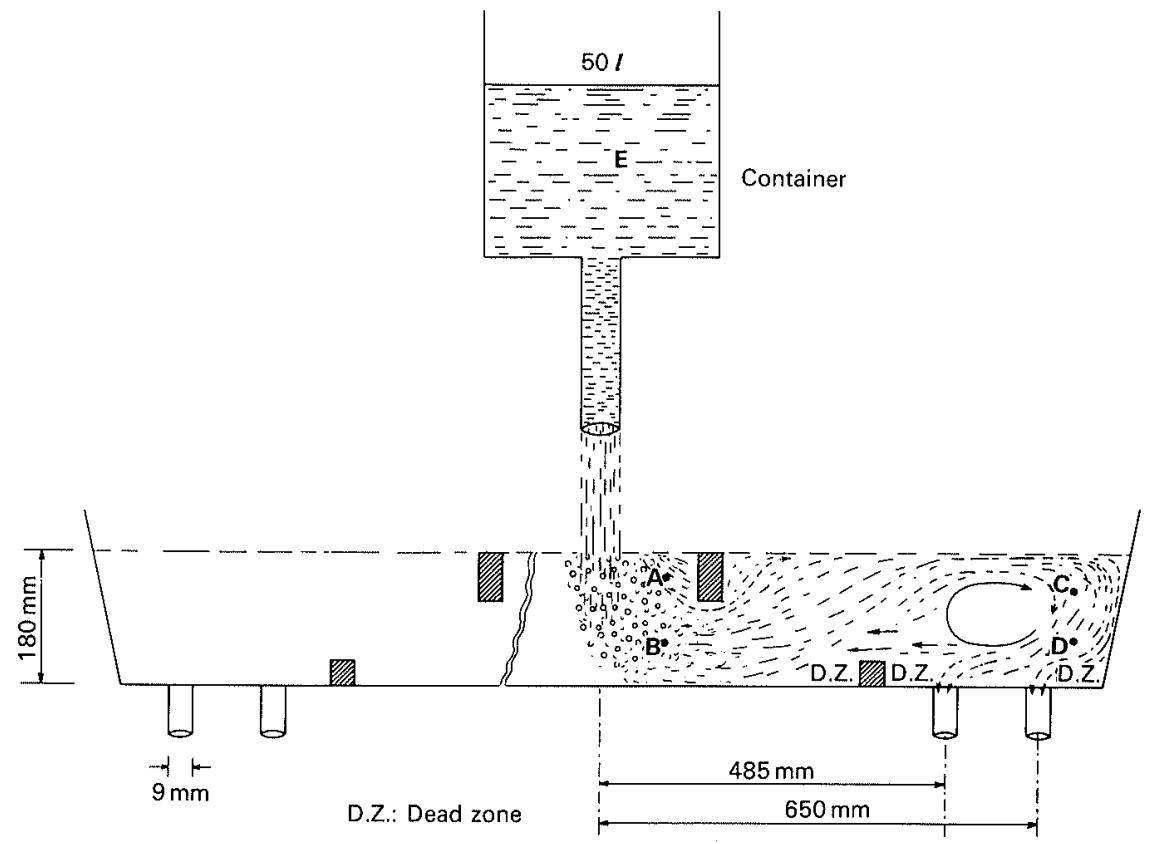

Fig. 1. Sketch showing the experimental model tundish with flow and thermal profile. A, B, C and D are locations where the temperatures were recorded at regular intervals of time. 


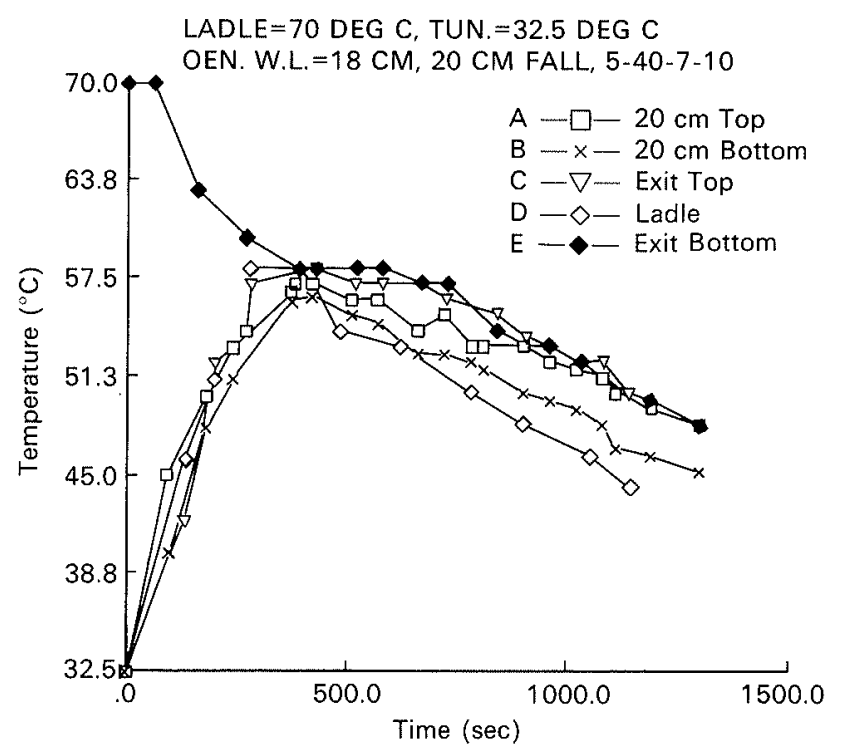

Fig. 2. Temperature profiles in a 4-strand continuous casting model tundish in the case of teeming from uninsulated ladle subject to temperature drop.

perature over the teeming operation in actual plant. The temperature at $\mathrm{A}$ shows a parabolic rise and reaches a peak of $57.0^{\circ} \mathrm{C}$ in $300 \mathrm{~s}$ with a gradual drop to $50^{\circ} \mathrm{C}$ in the next $1000 \mathrm{~s}$. Thereafter the rate drops during the course of the experiment. A small rise of temperature was observed between $500-650 \mathrm{~s}$.

The temperature profile at $\mathrm{B}$ showed a linear rise of $4.1^{\circ} \mathrm{C} / \mathrm{min}$ upto $200 \mathrm{~s}$ reaching a peak of $56^{\circ} \mathrm{C}$ followed by smooth drop to $43^{\circ} \mathrm{C}$ at $1300 \mathrm{~s}$. It may be noted that from $500 \mathrm{~s}$ onwards the temperature profile follows the profile of drop in the ladle temperature within $1.5^{\circ} \mathrm{C}$.

The pattern of change in temperature at $\mathrm{C}$, the location above the outer orifice is similar to that at B upto $200 \mathrm{~s}$ followed by a steeper rise after $300 \mathrm{~s}$ reaching a peak value of $57^{\circ} \mathrm{C}$. Thereafter the profile merges with the profile at $\mathrm{D}$ located near the outer orifice.

The profile at $\mathrm{D}$ shows a more rapid rise of temperature than the profiles at B and C upto $200 \mathrm{~s}$ followed by a steep rise at $300 \mathrm{~s}$ to $59^{\circ} \mathrm{C}$ at which temperature thermal stabilisation occurs and merges with the profile at $\mathrm{C}$ located in the same plane.

A significant observation is the persistent temperature difference between $\mathrm{A}$ and $\mathrm{B}$ loactions, the temperature at $A$ remaining always higher than at $B$. Also at $400 \mathrm{~s}$ the temperatures at A, B, C, D and the ladle temperature E come closer to each other, thereafter branch. However, $\mathrm{C}$ and $\mathrm{D}$ have identical temperature profile and the temperatures remain higher than at other locations.

\subsection{Tracer Response}

Response of tracer at the inner and outer orifices at regular interval of time after injection of the acid was monitored upto $800 \mathrm{~s}$ and plotted in Fig. 3 as a function of time. It may be pointed out that the acid injection was done immediately after the hot water stream from the container was released to the tundish to establish correlation, if any, between the tracer response and the temperature profile. The following points may be noted from the Fig. 3.

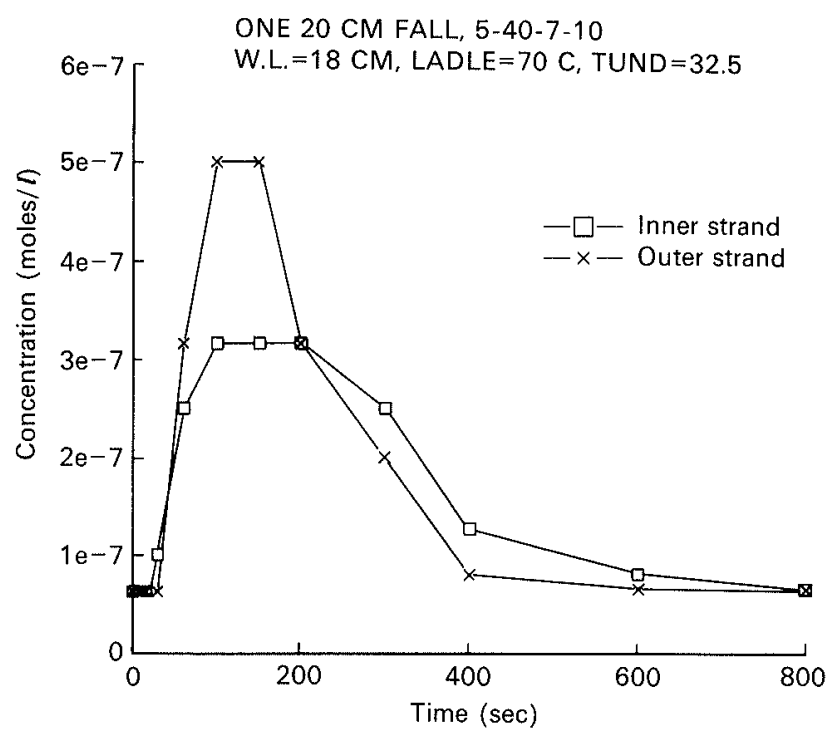

Fig. 3. Tracer response in model tundish under conditions of dropping temperature during teeming from uninsulated ladle.

(1) There is a delay time of $60 \mathrm{~s}$ before any response is noted at the orifices.

(2) Steep rise of concentration between 60 and $100 \mathrm{~s}$ is noticed in both inner and outer orifices. The outer concentration peak is more than the inner. At about $200 \mathrm{~s}$ inner concentration supercedes the outer and remains higher upto $800 \mathrm{~s}$ where both inner and outer concentrations become identical.

(3) Between 100-150 s outer concentration remains at the peak value but the inner concentration steeply drops and remains constant between 400-600 s. From $200-600 \mathrm{~s}$ the drop in concentration at both inner and outer is similar but the values of inner concentrations remain higher but at $800 \mathrm{~s}$ they merge.

\section{Discussions}

The relatively rapid rise of temperature at A compared to $\mathrm{B}, \mathrm{C}$ and $\mathrm{D}$ is due to the predominance of the influence of the incoming hot stream from the container displacing the existing cold water. The other locations are adjacent to dead zones which are relatively colder where the convective heat transfer lowers the temperature.

The persistence of nearly constant temperature difference between $\mathrm{A}$ and $\mathrm{B}$ on the one hand and $\mathrm{C}$ and $\mathrm{D}$ on the other emphasises the fact that complete thermal homogenisation throughout the tundish may not be realised for a very long time. However, the temperatures at $A$ and $C$ reach nearly identical values after $400 \mathrm{~s}$ and the temperatures merge with $\mathrm{D}$ profile, whereas the temperatures at $\mathrm{A}$ and $\mathrm{B}$ do not merge indicating a distinct stratification zones as shown in the Fig. 1.

Above the outer orifice upto $250 \mathrm{~s}$ the rise in the temperature at $\mathrm{C}$ is similar to that at $\mathrm{B}$ because the stream at $\mathrm{B}$ follows the path shown in the Fig. 1 and reaches $\mathrm{C}$ quickly. These have been observed through dye experiments also (not reported in this communication). The steep rise at $300 \mathrm{~s}$ is due to the preferential flow for a short period. 
The temperature above outer orifice remain higher than those at $\mathrm{A}$ and after $400 \mathrm{~s}$ and onwards till the end of experiment. Around this time there is considerable drop in ladle temperature also. In fact ladle temperature becomes lower than the tundish temperature. This steep drop in ladle temperature brings about a significant effect on inclusion floatation in actual practice.

The temperature at B follows closely the ladle temperature after about $500 \mathrm{~s}$ but remains slightly higher throughout. This establishes the fact that the influence on outer strand is marked and persists for longer time.

When the tracer results of Fig. 3 are compared with thermal profile of Fig. 2 in the corresponding time intervals, it can be seen that drop in concentration coincides with the region in the temperature profile where all the temperatures tend to have close values. From $800 \mathrm{~s}$ onwards the temperatures at $\mathrm{A}, \mathrm{C}$ and $\mathrm{D}$ as well as the concentrations of the inner and outer orifices have similar trends. Between $400-800 \mathrm{~s}$ the drop in the rate of concentration and temperature is due to the decay in concentration of tracer.

\section{Conclusions}

Due to the inherent temperature drop in the ladle during teeming operation in actual CC plant a buoyancy effect is experienced by the incoming stream. This is due to the density difference and difference in specific heat between the incoming stream from the ladle and the current liquid in the tundish. It is also observed that the bottom temperature of the tundish directly below the incoming stream remains most of the time lower. This has a significant influence on inclusion floatation. Thermal stratification also influences stratification of concentration. Finally the drop in ladle temperature does not seem to have any influence on the outlet temperature for a considerable length of time.

\section{Acknowledgement}

The authors owe their gratitude to the Workshop staff for fabricating the model and to the Director National Metallurgical Laboratory, for permission to publish this work

\section{REFERENCES}

1) T. Robertson and A. Perkins: Ironmaking Sleelmaking, 13 (1986), No. 6, 13, 301.

2) R. Baker and W. R. Irving: Ironmaking Steelmaking, 8 (198 I), 216.

3) F. Kemeny, D. J. Harris and A. MacLean: Continuous Casting of Steel, Proc. 2nd Technical Conf. AIME, (1981).

4) S. Chakrabotry and Y. Sahai: Metall. Trnas., 23B (1992), 153.

5) J. Szekely and O. J. Ilegbusi: The Physical and Mathematical Modeling of Tundish Operations, Springer Verlag, (1989).

(Received on November 16, 1992; accepted in final form on November I6, 1992)

K. M. GODIWALLA, S. K. SINHA ${ }^{1)}$ and C. S. SIVARAMAKRISHNAN ${ }^{1)}$

Computer Applications Divisions, National Metallurgical Laboratory, Jamshedpur-831007, India.

1) Materials Processing Division, National Metallurgical Laboratory, Jamshedpur-831007, India. 